\title{
Study of Macular Thickness Using Spectral Domain Optical Coherence Tomography in Healthy Indian Subjects
}

\author{
Authors \\ Dr Manushree Gautam, Dr Kamlesh Khilnani, Dr Reetika Saxena \\ Email:dr.manushreegautam@gmail.com, khilnanikamlesh@gmail.com, reetikasaxena123@yahoo.co.in
}

\begin{abstract}
Purpose: To generate normative data for SD-OCT (Topcon 3D OCT 2000) estimated macular thickness in Indian eyes and establish its relation with age sex and refractive error.

Materials and methods: In this cross sectional, observational, hospital based study 800 eyes of 400 healthy Indian individuals underwent a macula OCT scan using Topcon SD OCT. Macular thickness was measured in 9 ETDRS regions.The effect of age, sex, refractive error on foveal thickness was determined.

Results: The mean central foveeal thickness was $226.4025 \pm 22.5063 \mu \mathrm{m}$. Males were found to have a significantly thicker macula $(P<0.05)$ than females with the central foveal thickness of $229.8153 \pm 21.4222$ vs $220.7748 \pm 23.14742$. Central foveal thickness was found to have very weak correlation with age which was not statistically significant. All other regions (the parafoveal and perifoveal thickness) showed statistically significant negative correlation with age.

Conclusion: We provide the largest normative data for SD OCT Topcon 3D OCT 2000. We also suggest that demographic factor like gender should be considered while interpreting any OCT measurements. The normal range of central macular thickness for Indian population should be $181 \mu \mathrm{m}$ to $270 \mu \mathrm{m}$ for Topcon SD OCT. Age and refractive error do not show a significant correlation with central macular thickness.

Keywords- Topcon 3D OCT 2000, macular thickness, SD-OCT.
\end{abstract}

\section{INTRODUCTION}

Optical coherence tomography (OCT) is a new diagnostic technology for high-resolution, crosssectional, quantitative imaging of the retina. ${ }^{[1]}$ OCT is a non-invasive non-contact technique which uses near infrared low coherent light passing through a Michelson interferometer to obtain two dimensional images of the retina and optic nerve head. ${ }^{[1],[2]}$

The RT measurements obtained by SD-OCT are consistently greater than those obtained by TDOCT. RT measurement differences may also vary by SD-OCT model. Consideration of these measurement differences is essential when OCTdetermined RT measurement data are used in clinical settings. ${ }^{[3]}$

All instruments use vitreoretinal interface or internal limiting membrane as Inner retinal border whereas Outer retinal boundary varies with different machines. There are four hyper reflective outer retinal layers. (Christine.A. Crusio)

1. External limiting membrane

2. Inner Segment-Outer Segment junction of photoreceptors 
3. OS tips and apical processes of RPE (basal complex)

4. RP-Bruchs complex

Thus various models of SD-OCT also differ in their measurement due to different retinal segmentation algorithms used. Macular thickness measurements using different OCT systems are not interchangeable ${ }^{[4,5,6-10]}$. We used the Topcon SD-OCT, which uses the inner border of RPE, where the outer segment tips meet the apical processes of RPE (basal complex) as the outer retinal boundary for macular thickness measurements.

Ethnic differences in macular thickness and volume have been described in a number of studies. [11-16] Central and inner macular thickness and volume were shown to be significantly thinner in blacks and Asians than in whites, not only in adults ${ }^{[13-16]}$ but also in children. ${ }^{[11,12]}$.

According to Tiwari et al, age was positively correlated with the mean thickness of the central macula but negatively correlated with the inner and outer macular thicknesses ${ }^{[17]}$. Similar findings have been reported in previous studies by, Xin Rong Duan et al, Guedes Vet al and Sung KR et al $[18,15,19]$. but inconsistent with others, ${ }^{[20,13,14,21,22,23]}$

Hence there are non cnclusive reports on correlation of macular thickness with age.

In the study by Tewari et al. ${ }^{[17]}$ and Grover et al ${ }^{[24]}$ no significant difference was seen in the average foveal thickness and minimum foveal thickness in men and women. However, other similar studies by Song et al. ${ }^{[25]}$ Wong et al ${ }^{[26]}$ and Massin et al. ${ }^{[27]}$ found males to have significantly higher average retinal thickness as compared to females.

A number of recent studies show that refractive errors do not correlate significantly with central retinal thickness measurements [26, 28, 3, 29] Refraction was not found to have any significant effect on macular thickness, in studies by Tewari et al ${ }^{[17]}$., and Massin et al. ${ }^{[21]}$ Lim et al. ${ }^{[30]}$ in their study on myopes found that myopes had thinner parafovea and thicker foveas.
Therefore, data documenting normal macular measurements and variations associated with demographic and ocular variables in healthy Indian subjects on SD OCT are imperative to clinicians around the world to help them make informed decisions on pathologic changes in this ethnic group.

\section{MATERIALS AND METHODS}

This was a cross sectional, observational, hospital based study. 800 eyes of 400 healthy volunteers were recruited from the outpatient department of SMS Medical College, jaipur from November 2011 to November 2013. Macular thickness was measured using SD OCT (Topcon3D OCT2000). Informed consent was taken from all participants using consent form. All subjects underwent a complete ophthalmic examination including best corrected visual acuity estimation, slit lamp examination, non contact tonometry, dilated stereoscopic fundus examination.

Exclusion Criteria

1. age $<5$ yrs

2. BCVA $<6 / 6$ on Snellen's visual acuity chart

3 . eyes with media opacities preventing fundus assessment

4. IOP $>21 \mathrm{~mm} \mathrm{Hg}$

5. Patients with systemic diseases known to affect macula : diabetes, hypertension

6. Patients on medications known to cause maculopathy e.g.chloroquine

7. Patients with known neuro-ophthalmologic disease

All participants were subjected to macular imaging using Spectral Domain OCT following papillary dilatation. Both eyes of each participant was included in the study. The OCT images were taken using good centration. The Radial 3D OCT scan was used.

Statistical analysis was performed using t test and Pearsons correlation. Where indicated, linear regression was used to describe parametric associations and to generate graphic representations of the same. 


\section{JMSCR Vol||4||Issue||02||Page 9421-9431||February}

\section{RESULTS}

Prospective data on the macular thickness of 418 subjects were recorded. However, 18 patients had to be excluded from the final analysis due to poor scan quality $<60(\mathrm{n}=6)$, presence of minor retinal pigment epithelial irregularities $(\mathrm{n}=3)$, early epiretinal membrane ( $\mathrm{n}=3)$, non-clinically detectable small serous pigment epithelial detachment $(n=2)$, and poor centration of the ETDRS grid $(n=4)$. Eight hundred eyes of 400 subjects aged between 5 to 73 years were evaluated. The baseline parameters are shown in [Table 1]. The visual acuity of all 400 subjects for each eye was $6 / 6$.

The macular thickness was determined in 9 ETDRS regions. The means, standard deviations, and ranges are shown in [Table 2]. Looking at the macular topography, the fovea was the thinnest area
$(226.4025 \pm 22.5063 \mu \mathrm{m})$. The inner macula was thicker than outer macula in all four regions superior, inferior, nasal and outer $(\mathrm{p}<0.001)$,thus the retina thinned towards the periphery. The nasal macula (inner and outer) was found to be significantly thicker $(p<0.001)$ than the temporal macula. The superior quadrant was the thickest amongst all nine ETDRS regions. In the inner region of the macula superior quadrant was thickest, followed by the nasal, inferior and temporal quadrants. In contrast, in the outer region, the nasal quadrant was the thickest, followed by the superior, inferior and temporal quadrants.

Preliminary statistical analysis showed no difference in macular thickness between right and left eyes in any of the ETDRS regions.

Table 1:.Demographic data

\begin{tabular}{|l|l|}
\hline Baseline Parameters & Subjects $\mathrm{n}=400$, Eyes $\mathrm{N}=800$ \\
\hline Male: female & $498: 302$ \\
\hline Mean age (SD) in years & $32.18(13.14)$ \\
\hline Range in years & $5-73$ \\
\hline Mean spherical refractive error(SD) D & $0.11(1.08)$ \\
\hline Range of refractive error & -4 to $+3 \mathrm{D}$ \\
\hline
\end{tabular}

Table -2 Macular Thickness In Nine ETDRS Region

\begin{tabular}{|l|l|l|l|l|l|l|l|l|l|}
\hline Statistics & $\mu \mathrm{m}$ & & & & & & & & \\
\hline & Central & NIM & TIM & SIM & IIM & NOM & TOM & SOM & IOM \\
\hline & 226.402 & 297.141 & 283.606 & 298.318 & 291.671 & 277.808 & 248.552 & 261.732 & 257.747 \\
Mean & 5 & 3 & 3 & 8 & 3 & 8 & 5 & 5 & 5 \\
\hline Std. & & & 22.3256 & 20.9088 & & 19.5487 & 19.5808 & 16.6582 & 17.7380 \\
Deviation & 22.5063 & 21.3919 & 4 & 2 & 21.9822 & 2 & 3 & 7 & 1 \\
\hline Range & 171 & 160 & 236 & 166 & 218 & 227 & 235 & 184 & 205 \\
\hline Minimum & 141 & 187 & 158 & 182 & 177 & 157 & 113 & 163 & 159 \\
\hline Maximum & 312 & 347 & 394 & 348 & 395 & 384 & 348 & 347 & 364 \\
\hline
\end{tabular}


Table 3: Comparison On Basis Of Gender

\begin{tabular}{|l|l|l|l|l|l|l|l|}
\hline $\begin{array}{l}\text { ETDRS } \\
\text { region }\end{array}$ & Sex & N & Mean & $\begin{array}{l}\text { Std. } \\
\text { Deviation }\end{array}$ & $\begin{array}{l}\text { Std. Error } \\
\text { Mean }\end{array}$ & t value & \\
\hline Central & Male & 498 & 229.8153 & 21.42222 & 0.959953 & 5.611646 & S \\
\hline & Female & 302 & 220.7748 & 23.14742 & 1.331984 & & \\
\hline NIM & Male & 498 & 301.6205 & 19.49458 & 0.873573 & 7.891428 & $\mathbf{S}$ \\
\hline & Female & 302 & 289.755 & 22.34477 & 1.285797 & & \\
\hline TIM & Male & 498 & 287.5281 & 20.43038 & 0.915507 & 6.545278 & $\mathbf{S}$ \\
\hline & Female & 302 & 277.1391 & 23.80082 & 1.369583 & & \\
\hline SIM & Male & 498 & 302.1687 & 19.47634 & 0.872755 & 6.878849 & $\mathbf{S}$ \\
\hline & Female & 302 & 291.9702 & 21.66084 & 1.246441 & & \\
\hline IIM & Male & 498 & 295.3936 & 21.90564 & 0.981615 & 6.297365 & $\mathbf{S}$ \\
\hline & Female & 302 & 285.5331 & 20.72788 & 1.192756 & & \\
\hline NOM & Male & 498 & 279.6285 & 17.52723 & 0.785414 & 3.403379 & $\mathbf{S}$ \\
\hline & Female & 302 & 274.8079 & 22.19596 & 1.277234 & & \\
\hline TOM & Male & 498 & 251.992 & 17.75895 & 0.795797 & 6.544828 & $\mathbf{S}$ \\
\hline & Female & 302 & 242.8808 & 21.09886 & 1.214103 & & \\
\hline SOM & Male & 498 & 263.4137 & 15.76582 & 0.706483 & 3.694407 & $\mathbf{S}$ \\
\hline & Female & 302 & 258.9603 & 17.71475 & 1.019369 & & \\
\hline IOM & Male & 498 & 259.8775 & 17.51766 & 0.784985 & 4.411571 & $\mathbf{S}$ \\
\hline & Female & 302 & 254.2351 & 17.56774 & 1.01091 & &
\end{tabular}

\section{COMPARISON ON BASIS OF GENDER}

Females were found to have a significantly thinner macula $(P<0.05)$ than males in all 9 ETDRS regions as depicted in table 3 . The central foveal thickness was found to be $229.8153 \pm 21.4222$ vs $220.7748 \pm 23.14742$ for males vs females. (table 3)

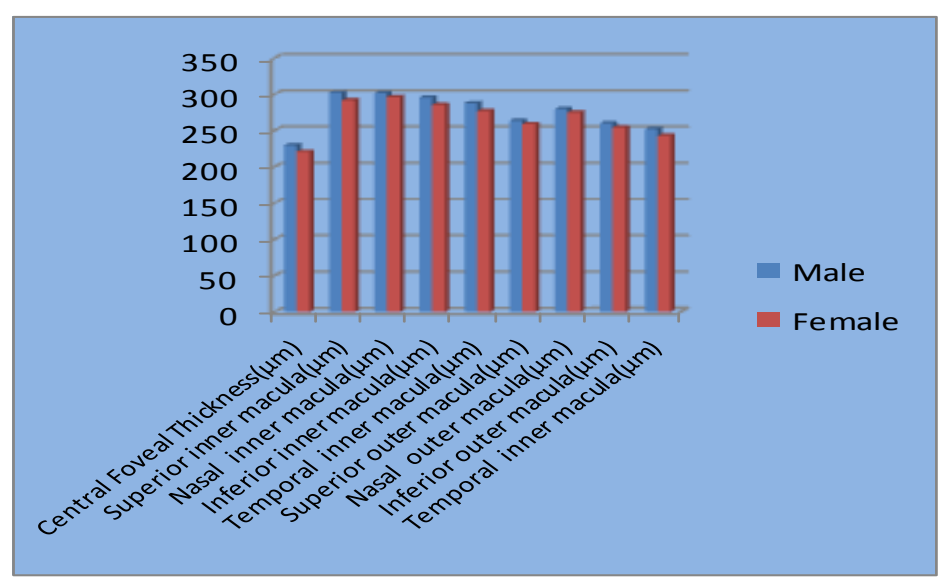

partial correlation as shown in table 4. Macular OCT Parameter in the Study group and their comparison with age using Pearson ' $r$ '.

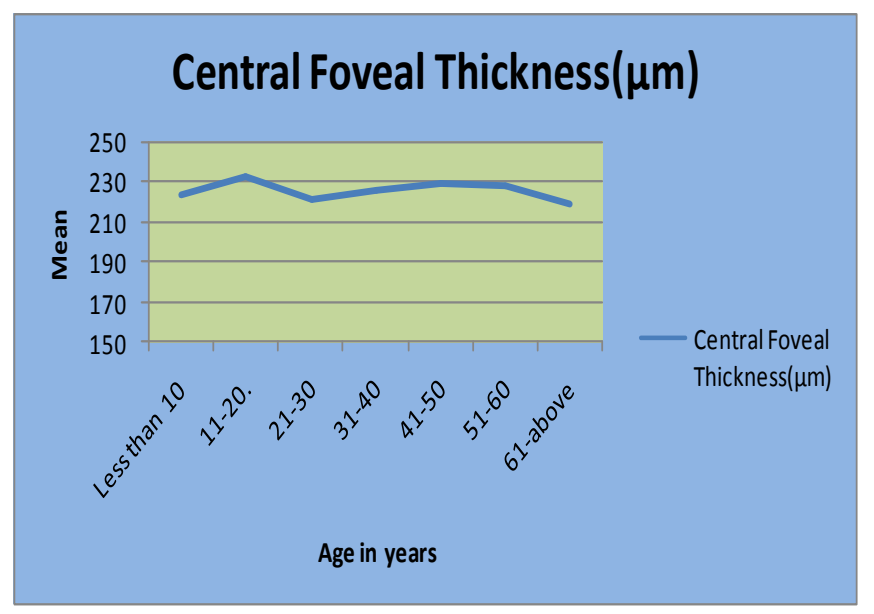

\section{Correlation with age}

Central foveal thickness was found to have very weak correlation with age which was not statistically significant. All other regions (the parafoveal and perifoveal thickness) showed statistically significant negative correlation with age, when analyzed using pearsons coefficient of 
Table 4: Correlation with age

\begin{tabular}{|c|c|c|c|c|c|}
\hline ETDRS region & $\begin{array}{l}\text { Minimu } \\
\mathrm{m}\end{array}$ & Maximum & $\begin{array}{lr}\text { Mean } & \text { retinal } \\
\text { Thickness } & \text { Mean } \\
\pm \text { S.D }(\mu \mathrm{m}) & \end{array}$ & Pearson ' $r$ ' & \\
\hline $\begin{array}{ll}\text { Central } & \text { Foveal } \\
\text { Thickness } & \\
\end{array}$ & 141 & 312 & $226.4025 \pm 22.5063$ & -0.04552 & $\mathrm{P}=0.198353$ \\
\hline Superior inner macula & 187 & 347 & $297.1413 \pm 21.3919$ & -0.05014 & $\mathrm{P}=0.156523$ \\
\hline Nasal inner macula & 158 & 394 & $283.6063 \pm 22.32564$ & -0.16299 & $\mathrm{P}=0.001$ \\
\hline Inferior inner macula & 182 & 348 & $298.3188 \pm 20.90882$ & -0.24477 & $\mathrm{P}=0.001$ \\
\hline $\begin{array}{l}\text { Temporal inner } \\
\text { macula }\end{array}$ & 177 & 395 & $291.6713 \pm 21.9822$ & -0.21755 & $\mathrm{P}=0.001$ \\
\hline Superior outer macula & 157 & 384 & $277.8088 \pm 19.54872$ & -0.15579 & $\mathrm{P}=0.001$ \\
\hline Nasal outer macula & 113 & 348 & $248.5525 \pm 19.58083$ & -0.12989 & $\mathrm{P}=0.05$ \\
\hline Inferior outer macula & 163 & 347 & $261.7325 \pm 16.65827$ & -0.20005 & $\mathrm{P}=0.001$ \\
\hline $\begin{array}{l}\text { Temporal inner } \\
\text { macula }\end{array}$ & 159 & 364 & $257.7475 \pm 17.73801$ & -0.15569. & $\mathrm{P}=0.001$ \\
\hline
\end{tabular}

All areas except the fovea had a decline with advancing age. The central foveal thickness did not correlate with age with a more or less linear graph. The only exception being average CFT in 11 to 20 years of age which shows an increase, though not statistically significant.

\section{CORRELATION WITH REFRACTIVE ERROR}

There was no significant correlation between macular thickness and refractive error in hypermetropic eyes(upto + 4D) In myopic eyes thickness in central macula and in outer temporal region was positively correlated with refractive error while no other region showed statistically significant correlation(upto - 4D).

\section{DISCUSSION}

\section{Normal Macular Tomography}

In our study, the central macular thickness was 226.4025 $\pm 22.5063 \mu \mathrm{m}$. Previous study on Indian eyes using Stratus OCT by Tewari et al. ${ }^{[17]}$ showed a thinner central foveal thickness of $149.16 \pm 21.15 \mu \mathrm{m}$. the discripency, can be partly explained by difference in retinal algorithms of Stratus OCT and Topcon 3D OCT. Further difference can be attributed to demographics (proportion of male subjects and age distribution) and small sample size in previous study.
In our study, the fovea was the thinnest area $(226.4025 \pm 22.5063 \mu \mathrm{m})$. The inner macula was thicker in all four quadrants ie superior, inferior nasal and temporal compared to outer macula $(\mathrm{p}<0.001)$, thus the retina thinned towards the periphery. The nasal macula (inner and outer) was found to be significantly thicker $(p<0.001)$ than the temporal macula. The superior quadrant was the thickest in the inner region of the macula, followed by the nasal, inferior and temporal quadrants. In contrast, in the outer region, the nasal quadrant was the thickest, followed by the superior,inferior and temporal quadrants. The observed macular thickness parameters of being thinnest at the fovea with an increase in the parafoveal area with decrease in perifoveal thickness are consistent with the normal anatomic contour and mirrors previous reports on OCT of the normal macula in the Caucasians ${ }^{[31,20]}$ and chinese population. ${ }^{[18]}$ Previous studies using different types of OCT or retinal thickness analyzer also reported a similar pattern of macular thickness by regions, which is speculated to be related to the crowding of nerve fibers within the inner region [32,17,11,33,29,12,34,35,15,36,21,37] and along the papillomacular bundle within the outer region of the macula. ${ }^{[32,11]}$

Using the criteria of mean \pm 2 SDs, which includes $95 \%$ of the population, we suggest that $181 \mu m$ to $270 \mu m$ be taken as the normal range 
for central foveal thickness in the Indian population for Topcon SD OCT. This implies that average CFT being $\mathbf{2 2 6 . 4 0 2 5}$, any patient with macular thickness of below $180 \mu \mathrm{m}$ or above 270 $\mu \mathrm{m}$ should be considered outside normal limits and should be further evaluated.

In other studies done using Topcon OCT Mehreen Adhi et al on subjects from pakistan, foveal thickness of $229.01 \pm 20.464 \mu \mathrm{m}$ was found. [38] Giani et al ${ }^{[07]}$ recently reported foveal thickness of $229 \pm 24 \mu \mathrm{m}$, while Sull AC et al ${ }^{[04]}$ reported a foveal thickness of $231 \pm 16 \mu \mathrm{m}$ in healthy subjects from New England using Topcon OCT system. However, Hyang et al ${ }^{[08]}$ reported foveal thickness of $221.76 \pm 15.95$, and Bruce et al [39] reported foveal thickness of $244.83 \pm 17.84$ $\mu \mathrm{m}$ in healthy subjects using Topcon OCT. However, in a study from Wisconsin, New York the CFT was found to be $274.3 \pm 72.4 \mu \mathrm{m}$ using Topcon OCT[40] . The same study showed CFT using stratus OCT as 249.8 $\pm 72.4 \mu \mathrm{m}$. This difference in measurements can be explained on ethnic grounds.

\section{Correlation of Macular Thickness with age}

In our study, the central foveal thickness did not correlate significantly with age. $(\mathrm{r}=-0.045$, $\mathrm{p}=0.198)$ However, in all other regions (parafoveal and perifoveal) thickness showed a significant negative correlation with age $(\mathrm{r}=-0.05$ to $-0.244, p=0.001$ to 0.156 ). These results suggest that young adults tend to have a deeper foveal depression and relatively thick inner and outer macular regions, whereas older adults tend to have less variation in macular thickness with a smaller magnitude in thickness changes from the foveola toward the central macula and inner and outer macular regions. The decreased thickness variation outside the central macula may result from the loss of ganglion cell and the thinning of the retinal nerve fiber layer associated with aging, which cannot be reflected in the central foveal area because there is no retinal nerve fiber layer. ${ }^{[19]}$ This decline in the retinal thickness with age is also supported by histologic decrease in the density of phodtoreceptors, ganglion cells, and retinal pigment epithelial cells with age. [41,42].

All areas except the central fovea had a decline with advancing age. The central foveal thickness did not correlate with age with a more or less linear graph. The only exception being average CFT in 11 to 20 years of age which shows an increase, though not statistically significant. Besides central region, thickness was found to increase in all other regions also from $1^{\text {st }}$ to $2^{\text {nd }}$ decade of life. Eriksson $U$ et al ${ }^{[43]}$ found similar pattern of increase in foveal thickness. The age related thinning

of the macula was not found in children, 5-16 yearsof age . In fact, there was a trend towards a retinal thickening with age in this group. Huynh et al. examined 1,543 six-year-old children. ${ }^{[44]}$ The central macular thickness reported in their study was thinner $(194 \mu \mathrm{m})$ than in the present study, and a statistically significant positive correlation with age was found. One could speculate that this apparent 'thickening' in early age could be an effect of the developing macula in childhood ${ }^{[45,46]}$ resulting in a slight thickening of the central retina before it is fully developed, but the finding could also be due to algorithm problems in a growing eye.

The negative correlation between age and parafoveal and perifoveal macular thickness in our study was consistent with other studies. ${ }^{[31,47 \text { and } 48]}$ that showed significant association between age and macular thickness in all ETDRS areas, except the center

Tiwari et al ${ }^{[17]}$ had similar findings for inner and outer macula but showed positive correlation of foveal thickness with age. According to J Huang et al, age was positively correlated to retinal thickness on some 49but not all subfields. The increased variation in central macular thickness in older persons compared with younger persons may be related to the thickening of the internal limiting membrane and the centripetal force of the posterior vitreous resulting in elevation of the fovea with aging ${ }^{[33]}$. In another study, a 
significant increase in center point foveal thickness and mean foveal thickness with age. They have suggested the presence of interstitial edema from foveal capillary dropout with age as a probable reason. It is likely that individual retinal layers (like the RNFL) are preferentially affected by age and that this is not detected in measurements of the whole retina. ${ }^{[50]}$ However we did not find any significant change in central macular thickness with age.

In contrast, few studies ${ }^{[51,08,04,38,03]}$ failed to show a statistically significant association between retinal thickness and age, which may be due to the small sample size and the age distribution.

Thus, we suggest that parafoveal and perifoveal thickness tends to decrease with age but the central foveal thickness which is most widely used for clinical purposes is not affected by age.

\section{Comparison on basis of Sex}

Our study showed that men had greater central foveal thickness as compared to women $(P<0.05)$. Females were found to have a significantly thinner macula $(P<0.05)$ than males in all 9 ETDRS regions as depicted in table 3 . The central foveal thickness was found to be $229.8153 \pm 21.4222$ vs $220.7748 \pm 23.14742$ for males vs females.

In the study by Tewari et al. ${ }^{[17]}$ and Grover et $a l$. ,[24] no significant difference was seen in the average foveal thickness and minimum foveal thickness in men and women. However, other similar studies [25, 26, 27, 48, 49, 38,26, 03] found males to have significantly higher average retinal thickness as compared to females.. The presence of thinner foveas in females could probably explain the higher incidence of macular holes seen in them.

\section{Correlation with refractive error}

In our study, overall refractive error was not found to have any significant effect on macular thickness. There was no significant correlation between macular thickness and refractive error in hypermetropic eyes ( $p$ ranging from 0.039 to 0.039). In myopic eyes thickness in central macula and in outer temporal region was weakly positively correlated with refractive error while no other region showed statistically significant correlation ( $\mathrm{p}$ ranging from 0.07 to 0.15 ). This was similar to other studies ${ }^{[76,85.73]}$ A number of recent studies show that refractive errors and keratometry readings do not correlate significantly with central retinal thickness. ${ }^{[99,74,25,78]}$. Lim et al. ${ }^{[100]}$ in their study on myopes found that myopes had thinner parafovea and thicker foveas.

\section{CONCLUSION}

Keeping in view the various determinants of macular thickness. This is first study to use SD OCT (TOPCON 3D OCT 2000) with largest normative database for establishing macular thickness in Indians and to determine effect of age, sex and refractive error on it.

The macular thickness was determined in 9 ETDRS regions. The fovea was the thinnest area $(\mathbf{2 2 6 . 4 0 2 5} \pm \mathbf{2 2 . 5 0 6 3} \boldsymbol{\mu m})$. Using the criteria of mean \pm 2 SDs, which includes $95 \%$ of the population, we suggest that $181 \mu \mathrm{m}$ to $270 \mu \mathrm{m}$ be taken as the normal range for central foveal thickness in the Indian population for Topcon SD OCT.

Females were found to have a significantly thinner macula $(P<0.05)$ than males in all 9 ETDRS regions. The central foveal thickness was found to be $229.8153 \pm 21.4222$ vs $220.7748 \pm 23.14742$ for males vs females.

Central foveal thickness was found to have very weak correlation with age which was not statistically significant. All other regions showed statistically significant negative correlation with age.

There was no significant correlation between macular thickness and refractive error.

\section{References}

1. Pedut-Kloizman T, Paktera HM, Schuman JS, Szwartz JC, Hee MR. Ophthal Clin North Am 1998;11:465-87.

2. Huang D, Swanson EA, Lin CP, Schuman JS, Stinson WG, Chang W, at al. Optical 
coherence

tomography. Science 1991;254:1178-81.

3. Patrick J. Kelty, John F. Payne, Rupal H. Trivedi, Jason Kelty, Esther M. Bowie and Berdine M. Burger Macular Thickness Assessment in Healthy Eyes Based on Ethnicity Using Stratus OCT Optical Coherence Tomography. Invest. Ophthalmol. Vis. Sci. June 2008 vol. 49 no. 62668-2672.

4. Alan C. Sull, Laurel N. Vuong, Lori Lyn Price, Vivek J. Srinivasan, Iwona Gorczynska, James G. Fujimoto, Joel S. Schuman, and Jay S. Duker, Comparison of spectral/fourier domain optical coherence tomography instruments for assessment of normal macular thickness Retina. 2010 February; 30(2): 235.

5. Leung CK, Cheung CY, Weinreb RN, et al. Comparison of Macular Thickness Measurements between Time Domain and Spectral Domain Optical Coherence Tomography. Invest Ophthalmol Vis Sci. 2008;49: 4893-489.

6. Legarreta JE, Gregori G, Punjabi OS, Knighton RW, Lalwani GA, et al. Macular thickness measurement in normal eyes using spectral domain optical coherence tomography. Ophthalmic Surg Lasers Imaging 2008;39: S43-9.

7. Giani A, Cigada M, Choudhry N, Deiro AP, Oldani M, et al. Reproducibility of retinal thickness measurements on normal and pathologic eyes by different optical coherence tomography instruments. Am J Ophthalmol 2010;150: 815-24. doi:10.1016/j.ajo. 2010. 06.025.

8. Huang J, Liu X, Wu Z, Guo X, Xu H, et al. Macular and retinal nerve fiber layer thickness measurements in normal eyes with the Stratus OCT, the Cirrus HD-OCT, and the Topcon 3D OCT-1000. J Glaucoma 2011;20:118-25. doi:10.1097/IJG.0b013e3181d786f8.
9. Pierro L, Giatsidis SM, Mantovani E, Gagliardi M. Macular thickness interoperator and intraoperator reproducibility in healthy eyes using 7 optical coherence tomography instruments. Am J Ophthalmol 2010;150:199-204. doi:10.1016/j.ajo.2010.03.015.

10. Menke MN, Dabov S, Knecht P, Sturm V. Reproducibility of retinal thickness measurements in healthy subjects using spectralis optical coherence tomography. Am J Ophthalmol 2009;147:467-72. doi: 10.1016/j.ajo.2008.09.005

11. Huynh SC, Wang XY, Rochtchina E, Mitchell P. Distribution of macular thickness by optical coherence tomography: findings from a populationbased study of 6-year-old children. Invest Ophthalmol Vis Sci. 2006;47:2351-2357.

12. El-Dairi MA, Asrani SG, Enyedi LB, Freedman SF. Optical coherence tomography in the eyes of normal children. Arch Ophthalmol. 09;127:50-58.

13. Kelty PJ, Payne JF, Trivedi RH, et al. Macular thickness assessment in healthy eyes based on ethnicity using Stratus OCT optical coherence tomography. Invest Ophthalmol Vis Sci. 2008;49:2668-2672

14. El-Ashry M, Hegde V, James P, Pagliarini S. Analysis of macular thickness in British population using optical coherence tomography (OCT): an emphasis on interocular symmetry. Curr Eye Res. 2008; 33:693-699.

15. Guedes V, Schuman JS, Hertzmark E, et al. Optical coherence tomography measurement of macular and nerve fiber layer thickness in normal and glaucomatous human eyes. Ophthalmology. 2003;110:177-189.

16. Asefzadeh B, Cavallerano AA, Fisch BM. Racial differences in macular thickness in healthy eyes. Optom Vis Sci. 2007;84:941-945. 
17. Tewari HK, Wagh VB, Sony $\mathrm{P}$, et al. Macular thickness evaluation using the optical coherence tomography in normal Indian eyes. Indian $J$ Ophthalmol. 2004;52:199-204.

18. Xin Rong Duan, Yuan Bo Liang, David S. Friedman, Lan Ping Sun, Tien Yin Wong, Qiu shan Tao, Lingzhi Bao, Ning Li Wang, Normal Macular Thickness Measurements Using Optical Coherence Tomography in Healthy Eyes of Adult Chinese Persons: The Handan Eye Study Ophthalmology Volume August 2010;117 (8):1585-1594.

19. Sung KR, Wollstein G, Bilonick RA, et al. Effects of age on optical coherence tomography measurements of healthy retinal nerve fiber layer, macula, and optic nerve head. Ophthalmology. 2009;116:1119-1124.

20. Chan A, Duker JS, Ko TH, et al. Normal macular thickness measurements in healthy eyes using Stratus optical coherence tomography. Arch Ophthalmol. 2006;124:193-198.

21. Massin P, Erginay A, Haouchine B, et al. Retinal thickness in healthy and diabetic subjects measured using optical coherence tomography mapping software. Eur J Ophthalmol. 2002;12:102108.

22. Sanchez-Tocino H, Alvarez-Vidal A, Maldonado MJ, et al. Retinal thickness study with optical coherence tomography in patients with diabetes. Invest Ophthalmol Vis Sci. 2002;43:1588-1594.

23. Eriksson U, Alm A. Macular thickness decreases with age in normal eyes: a study on the macular thickness map protocol in the Stratus $\quad$ OCT. $\mathrm{Br} \quad J$ Ophthalmol. 2009;93:1448-1452.

24. Grover S, Murthy RK, Brar VS, Chalam KV. Normative data for macular thickness by high-definition spectral domain optical coherence tomography (Spectralis). Am J Ophthalmol 2009;148:266-71.

25. Song WK, Lee SC, Lee ES, Kim CY, Kim SS. Macular thickness variations with sex, age, and axial length in healthy subjects: A spectral domain-optical coherence tomography study. Invest Ophthalmol Vis Sci 2010;51:3913-18.

26. Wong AC, Chan CW, Hui SP. Relationship of gender, body mass index and axial length with central retinal thickness using optical coherence tomography. Eye 2005;19:292-7.

27. Massin P, Erginay A, Haouchine B, Mehidi AB, Paques M, Gaudric A. Retinal thickness in healthy and diabetic subjects measured using optical coherence tomography mapping software. Eur $J$ Ophthalmol. 2002;12(2):102-108.

28. Bressler NM, Edwards AR, Antoszyk AN, et al. Retinal thickness on Stratus optical coherence tomography in people with diabetes and minimal or no diabetic retinopathy. Am J Ophthalmol. 2008;145(5): 894-901.

29. Manassakorn A, Chaidaroon W, Ausayakhun S, et al. Normative database of retinal nerve fiber layer and macular retinal thickness in a Thai population. Jpn J Ophthalmol. 2008;52:450-456.

30. Lim MC, Hoh ST, Foster PJ, Lim TH, Chew SJ, Seah SK, et al. Use of optical coherence tomography to assess variations in macular retinal thickness in myopia. Invest Ophthalmol Vis Sci 2005;46:974-8.

31. Kanai K, Abe T, Murayama K, Yoneya S. Retinal thickness and changes with age. Nippon Ganka Gakkai Zasshi 2002;106:162-5.

32. Hee MR, Puliafito CA, Duker JS, et al. Topography of diabetic macular edema with optical coherence tomography. Ophthalmology. 1998;105(2)360-370.

33. Wu PC, Chen YJ, Chen $\mathrm{CH}$, et al. Assessment of macular retinal 
thickness and volume in normal eyes and highly myopic eyes with third-generation optical coherence tomography. Eye (Lond). 2008;22: 551-555.

34. Oshitari T, Hanawa K, AdachiUsami E. Changes of macular and RNFL thicknesses measured by Stratus OCT in patients with early stage diabetes. Eye (Lond). 2009;23:884-889.

35. Hsu SY, Tsai RK. Analysis of retinal nerve fiber layer and macular thickness measurements in healthy Taiwanese individuals using optical coherence tomography (Stratus OCT). $J$ Glaucoma. 2008;17:30-35.

36. Kanai K, Abe T, Murayama K, Yoneya S. Retinal thickness and changes with age [in Japanese]. Nippon Ganka Gakkai Zasshi. 2002;106:162-165.

37. Goebel W, Kretzchmar-Gross T. Retinal thickness in diabetic retinopathy: a study using optical coherence tomography (OCT). Retina. 2002;22:759-767.

38. Adhi M, Aziz S, Muhammad K, Adhi MI. Macular Thickness by Age and Gender in Healthy Eyes Using Spectral Domain Optical Coherence Tomography. PLoS ONE 2012;7(5):e37638. doi:10.1371/ journal.pone.0037638.

39. Bruce A, Pacey LE, Dharni P, Scally AJ, Barrett BT. Repeatability and Reproducibility of macular thickness measurements using fourier domain optical coherence tomography. Open Ophthalmol J 2009;3: 10-4.

40. Amitha Domalpally, Sapna Gangaputra, MPH; Qian Peng, Ronald P. Danis. Repeatability of Retinal Thickness Measurements Between Spectral-Domain and Time-Domain Optical Coherence Tomography Images in Macular Disease Ophthalmic Surgery, Lasers and Imaging Retina November/December 2010 Volume 41 · Issue 6: S34-S41.
41. Panda-Jonas S, Jonas JB, Jakobczyk-Zmija M. Retinal photoreceptor density decreases with age. Ophthalmol 1995;102:1853-9.

42. Gao H, Hollyfield JG. Aging of the human retina. Differential loss of neurons and retinal pigment epithelial cells. Invest Ophthalmol Vis Sci 1992;33:1-17.

43. Eriksson U, Holmström G, Alm A, Larsson E. A population-based study of macular thickness in full-term children assessed with Stratus OCT: normative data and repeatability. Acta Ophthalmol. 2009;87(7): 741-745.

44. Huynh SC, Wang XY, Rochtchina E, Mitchell P. Distribution of macular thickness by optical coherence tomography: findings from a populationbased study of 6-year-old children. Invest Ophthalmol Vis Sci 2006;47(6):2351-7.

45. Hendrickson AE and Yuodelis C. The morphological development of the human fovea. Ophthalmology 1984;91:603-612.

46. Yuodelis C and Hendrickson AE. A qualitative and quantitative analysis of the human fovea during development, Vision Res 1986; 26:847-855.

47. Manassakorn A, Chaidaroon W, Ausayakhun S, Aupapong S, Wattananikorn S. Normative database of retinal nerve fiber layer and macular retinal thickness in a Thai population. Jpn J Ophthalmol 2008;52:450-6.

48. Bindu Appukuttan, Anantharaman Giridhar, Mahesh Gopalakrishnan, Sobha Sivaprasad Normative spectral domain optical coherence tomography data on macular and retinal nerve fiber layer thickness in Indians IJO 2013.

49. Jingjing Huang, Xing Liu, Ziqiang Wu, Hui Xiao, Laurie Dustin, and Srinivas Sadda, Macular thickness measurements in normal eyes with time domain and fourier domain optical coherence tomography Retina. 2009 Jul-Aug; 29(7): 980-987. 
50. Amir H. Kashani Ingrid E. Zimmer-Galler Syed Mahmood Shah Laurie Dustin Diana V. Do Dean Eliott Julia A. Haller Quan Dong Nguyen Retinal Thickness Analysis by Race, Gender, and Age Using Stratus OCT American Journal of Ophthalmology Volume 149, Issue 3 , Pages 496-502.e1, March 2010.

51. Grover S, Murthy RK, Brar VS, Chalam $\mathrm{KV}$. Comparison of retinal thickness in normal eyes using Stratus and Spectralis Optical Coherence Tomography. Invest Ophthalmol Vis Sci 2010;51:2644-47. 